\title{
Identification of genetic markers associated with Gyrodactylus salaris resistance in Atlantic salmon Salmo salar
}

\author{
John Gilbey ${ }^{1,4, *}$, Eric Verspoor ${ }^{1,4},{\text { Tor Atle } \text { Mo }^{2} \text {, Erik Sterud }}^{2}$, Kjetil Olstad $^{2,5}$, \\ Sigurd Hytterød ${ }^{2}$, Catherine Jones ${ }^{3}$, Leslie Noble ${ }^{3}$ \\ ${ }^{1}$ Fisheries Research Services (FRS) Marine Laboratory, Victoria Road, Aberdeen AB11 9DB, UK \\ ${ }^{2}$ National Veterinary Institute, PO Box 8156 Dep., 0033 Oslo, Norway \\ ${ }^{3}$ University of Aberdeen, School of Biological Science, Department of Zoology, Tillydrone Avenue, Aberdeen AB24 2TZ, UK \\ ${ }^{4}$ Present address: FRS Freshwater Laboratory, Faskally, Pitlochry PH16 5LB, UK \\ ${ }^{5}$ Present address: The Natural History Museums and Botanical Garden (NHM), University of Oslo, PO Box 1172, \\ Blindern 0318 Oslo, Norway
}

\begin{abstract}
Gyrodactylus salaris Malmberg, 1957 is a freshwater monogenean ectoparasite of salmonids, first recorded in Norway in 1975 and responsible for extensive epizootics in wild Atlantic salmon Salmo salar L. The susceptibility of different populations of Atlantic salmon to G. salaris infection differs markedly, with fish from the Baltic being characterised as relatively resistant whereas those from Norway or Scotland are known to be (extremely) susceptible. Resistance to Gyrodactylus infection in salmonids has been found to be heritable and a polygenic mechanism of control has been hypothesised. The current study utilises a 'Quantitative trait loci' (QTL) screening approach in order to identify molecular markers linked to QTL influencing G. salaris resistance in B1 backcrosses of Baltic and Scottish salmon. Infection patterns in these fish exhibited 3 distinct types; susceptible (exponential parasite growth), responding (parasite load builds before dropping) and resistant (parasite load never increases). B1 backcross fish were screened at 39 microsatellite markers and single marker-trait associations were examined using general linear modelling. We identified 10 genomic regions associated with heterogeneity in both innate and acquired resistance, explaining up to $27.3 \%$ of the total variation in parasite loads. We found that both innate and acquired parasite resistance in Atlantic salmon are under polygenic control, and that salmon would be well suited to a selection programme designed to quickly increase resistance to G. salaris in wild or farmed stocks.
\end{abstract}

KEY WORDS: Gyrodactylus salaris · Atlantic salmon · Resistance · Linkage mapping • Quantitative trait loci Resale or republication not permitted without written consent of the publisher

\section{INTRODUCTION}

Gyrodactylus salaris Malmberg, 1957 is a freshwater monogenean ectoparasite of salmonids, first recorded in Norway in 1975 (Johnsen 1978), and responsible for extensive epizootics of wild Atlantic salmon Salmo salar L. By 1994, 38 rivers had become infected (Soleng \& Bakke 1995), rising to 45 in 2004 (Mo 2004, Mo \& Norheim 2005). The average density of salmon parr in infected rivers has fallen by around $86 \%$ (NOU 1999) with few, if any, salmon parr reaching the smolting stage in rivers where the parasite has occurred for some time (Johnsen \& Jensen 1991). This has led to an annual loss of 250 to $500 \mathrm{t}$ of salmon (NOU 1999) and a total cost exceeding 500 million US dollars (Bakke et al. 2004).

Recent years have seen research into genetic methods of Gyrodactylus salaris control based on the heterogeneity in susceptibility of different salmon stocks to $G$. salaris that has been noted in laboratory and wild studies (e.g. Bakke et al. 1990, 2002, Bakke \& MacKenzie 1993, Jansen \& Bakke 1993a,b, RintamäkiKinnunen \& Valtonen 1996, Cable et al. 2000, Dalgaard et al. 2003, 2004, Lindenstrøm et al. 2006).

Atlantic salmon consist of 3 groups, genetically distinct and geographically separated, situated in the 
Western Atlantic Ocean, the Eastern Atlantic Ocean and the Baltic (Stahl 1987, Bakke et al. 1990). Within these groups the species comprise multiple, genetically differentiated and, to a large extent, reproductively isolated river populations (Stahl \& Hindar 1988). There is virtually no migration of fish from the Baltic into the Eastern Atlantic, or vice versa (Christensen \& Larsson 1979). Population level genetic heterogeneity in resistance within and between salmon populations may thus be important in determining whether an epizootic takes place in a particular river (Pickering 1987), and for the future development of stocks resistant to the parasite (Bakke et al. 1999).

Most species of freshwater fish seem to be more susceptible to attack from parasites to which they have not been previously exposed (Dobson \& May 1987, Bakke et al. 1990). Heterogeneity in susceptibility of different salmon stocks, and of individuals of the same stock, to Gyrodactylus salaris has been noted in a number of studies, with fish from the Baltic being less susceptible than those of the Eastern Atlantic (Bakke et al. 1990, 2002, Bakke \& MacKenzie 1993, Jansen \& Bakke 1993a,b, Rintamäki-Kinnunen \& Valtonen 1996, Cable et al. 2000, Dalgaard et al. 2003, 2004, Lindenstrøm et al. 2006). The presence of the parasite in the Baltic since the last glacial period has exerted heavy selection pressure on local populations and has resulted in these populations developing an heritable resistance to infection (Bakke et al. 2002, Dalgaard et al. 2003), although even within the Baltic differences in population susceptibility have also been observed (Bakke et al. 2004). It is this heritable resistance to infection that has been proposed as a method for the control of $G$. salaris.

Identification of resistant individuals and of the genes involved in the host response to infection can be incorporated into selective breeding programme to produce stocks which are less susceptible to parasite attack (Jones et al. 2002). This natural resistance may then be commercially exploited (without the need for genetic engineering) using modern molecular genetic techniques to identify molecular markers for resistance. These markers may then be used to increase the efficiency of selective breeding programmes by an order of magnitude compared to traditional breeding programmes (Jones et al. 2002), something already achieved with resistant crop plants produced using this type of marker-assisted selection (e.g. Williams et al. 2001).

In this study the underlying genetic basis for individual and population level differences in resistance was examined using 'Quantitative trait loci' (QTL) analysis. Linkage maps were used to systematically search for chromosomal regions with significant statistical associations with parasite resistance, within salmon families created using hybrid male parents produced from stocks divergent in their ability to resist Gyrodactylus salaris.

\section{MATERIALS AND METHODS}

Line crosses. The fish used in this investigation were B1 backcross hybrids produced from the crossing of Baltic salmon from the river Neva, which have been shown to be relatively resistant to Gyrodactylus salaris infection (Bakke et al. 1990, Cable et al. 2000), and Scottish salmon from the river Conon, which have been shown to be extremely susceptible (Bakke \& MacKenzie 1993, Dalgaard et al. 2003). To obtain the experimental crosses, 2 Conon females were initially crossed with 2 Neva males to obtain a F1 hybrid generation. The following year a mature (precocious) hybrid F1 male was selected at random from each of 2 of the F1 families and crossed to a Neva female (Family 1) and a Conon female (Family 2), producing the 2 experimental B1 backcross families. Eggs and fish were maintained at the FRS Marine Laboratory Hatchery at Aultbea, Ross-Shire, until the fish were sent by airfreight to the National Veterinary Institute, Oslo, Norway, where the parasite challenge experiments were performed.

Gyrodactylus salaris exposure and rearing conditions. Fish were retained in family groups for $\sim 30 \mathrm{~d}$ to allow acclimatisation. At this stage the 1+ experimental fish were on average $85.1 \mathrm{~mm}( \pm 10.7 \mathrm{~mm} \mathrm{SD})$ and $10.3 \mathrm{~g}( \pm 3.7 \mathrm{~g})$. We then infected 50 fish from each family with $G$. salaris before individually isolating them in $10 \times 15 \times 20 \mathrm{~cm}$ mesh-bottomed plastic boxes, floating in four $100 \times 100 \times 50 \mathrm{~cm}$ fibre-glass tanks each containing $400 \mathrm{l}$ of water; or in individual net-covered plastic buckets with isolated water flows. Initial infection of all 100 experimental fish was carried out overnight in aerated $40 \times 40 \times 100 \mathrm{~cm}$ tanks. Groups of $\sim 35$ fish were retained in $\sim 101$ of water; G. salaris were added to the tanks on fins removed from heavily infected salmon.

Evaluation of Gyrodactylus salaris resistance/susceptibility. After $18 \mathrm{~h}$ (average), the start-infection was registered for every fish before they were moved to their respective experimental tanks. The infections were thereafter monitored at weekly intervals until Day 36, counting all parasites on the fins and body of the fish. Fish were anaesthetised in a $0.04 \%$ solution of chlorbutanol before the parasites were counted under a stereomicroscope in half the concentration of the anaesthetic. Chlorbutanol solutions were renewed after each fish counted. At the end of the experimental period all fish were killed with an overdose of anaesthetic and the sex determined by examination of 
gonadal tissue. Samples of adipose fin tissue were retained in ethanol for molecular analysis.

Genotyping and linkage-mapping. Each fish (including parents and grandparents) was screened at 39 microsatellite loci. The choice of which microsatellites to use was complicated by the unavailability at the time of a comprehensive linkage-map for the Atlantic salmon. The markers were thus chosen to cover all linkage groups in the partial linkage-map of Gilbey et al. (2004), and as many as possible from a provisional draft of the comprehensive linkage-map being produced by the SALMAP EU-project (B. Hoyheim pers. comm.; updated version now available at http://grasp.mbb.sfu.ca/). Recombination in male
Atlantic salmon is significantly reduced compared to females and shows the largest sex-specific recombination rate differences so far found in any vertebrate species (e.g. 3.92:1 female:male, Gilbey et al. 2004; see Wright et al. 1983, Johnson et al. 1987, Moen et al. 2004 for details of salmonid recombination). As it was the male fish that were informative in this study, and because of the very low levels of recombination within linkage groups of these fish, a single marker was chosen from each linkage-group identified with the available maps. Markers were chosen such that, where possible, they covered all of the 15 linkage-groups identified by Gilbey et al. (2004) and the 30 contained in the early SALMAP draft (Table 1).

Table 1. Salmo salar. Microsatellites used in analysis. Linkage-groups identified from linkage-map of Gilbey et al. (2004) and linkage-map of SALMAP. TD: Touchdown-PCR was used (see 'Materials and methods'). unl.: unlinked. nu: not used in linkage study

\begin{tabular}{|c|c|c|c|c|c|c|}
\hline Locus & $\begin{array}{l}\text { Linkag } \\
\text { Gilbey }\end{array}$ & $\begin{array}{l}\text { e-groups } \\
\text { SALMAP }\end{array}$ & Primers & $\begin{array}{c}\text { Annealing } \\
T\left({ }^{\circ} \mathrm{C}\right)\end{array}$ & $\begin{array}{c}\mathrm{MgCl}_{2} \\
\text { conc. }(\mathrm{mM})\end{array}$ & $\begin{array}{l}\text { GenBank } \\
\text { Acc. No. }\end{array}$ \\
\hline \multirow[t]{2}{*}{ Ssa202 } & 1 & 1 & F-CTTGGAATATCTAGAATATGGC & & & \\
\hline & & & R-TTCATGTGTTAATGTTGCGTG & 58 & 1.5 & U43695 \\
\hline \multirow[t]{2}{*}{ Ssa171 } & 2 & 4 & F-TTATTATCCAAAGGGGTCAAAA & & & \\
\hline & & & R-GAGGTCGCTGGGGTTTACTAT & 58 & 1.5 & U43693 \\
\hline \multirow{2}{*}{ Ssosl311 } & 3 & 2 & F-TAGATAATGGAGGAACTGCATTCT & & & \\
\hline & & & R-CATGCTTCATAAGAAAAAGATTGT & 55 & 1.5 & Z48597 \\
\hline \multirow[t]{2}{*}{ Ssa42 } & 3 & $\mathrm{nu}$ & F-TCTGGCTGTAAATCAGAATATA & & & \\
\hline & & & R-CAGCACATTTAAGTAACTTGAA & 52 & 1.5 & AF019174 \\
\hline \multirow[t]{2}{*}{ Ssa48 } & 4 & $10 / 22$ & F-AGTCTGTCTCCAGCCTCTTCTC & & & \\
\hline & & & R-ATGGCTTGTGGACTGTGAAGTA & 56 & 1.5 & AF019176 \\
\hline \multirow[t]{2}{*}{ Ssa11 } & 5 & $\mathrm{nu}$ & F-ATGACCAACAAATCAATGTGAC & & & \\
\hline & & & R-GGATTCTCTGAATGTGTTCGTC & TD & 1.5 & U58894 \\
\hline \multirow[t]{2}{*}{ Ssa14 } & 6 & 17 & F-CCTTTTGACAGATTTAGGATTTC & & & \\
\hline & & & R-CAAACCAAACATACCTAAAGCC & 57 & 1.5 & \\
\hline \multirow[t]{2}{*}{ Ssa164 } & 7 & 13 & F-TGTGTTTAGGATACATGCCATG & & & \\
\hline & & & R-ACAGCATTCCCCATACATACAG & 54 & 1.5 & AF019152 \\
\hline \multirow[t]{2}{*}{ SSsp3016 } & 8 & 9 & F-GGGCAGGCTAGGACAGGGCTAAGTC & & & \\
\hline & & & R-AGTAAGCCAGGGCAATAGCCTGCTTG & 62 & 1.5 & AF372820 \\
\hline \multirow[t]{2}{*}{ SSsp2201 } & 9 & 5 & F-TTTAGATGGTGGGATACTGGGAGGC & & & \\
\hline & & & R-CGGGAGCCCCATAACCTTACTAATAAC & 58 & 1.5 & AY081817 \\
\hline \multirow[t]{2}{*}{ Ssosl444 } & 10 & 3 & F-CCCACAAGGACAAAGTAATCCTCA & & & \\
\hline & & & R-CACGATTCTATTTCTCCCATCCAA & TD & 1.5 & Z49997 \\
\hline \multirow{2}{*}{ CmrSS1.22 } & 11 & $\mathrm{nu}$ & F-TCCTCGGCCAGCTGGTTCTTTA & & & \\
\hline & & & R-TGTGTACGCATGGATAGTCTC & 60 & 1.5 & AF020848 \\
\hline \multirow{2}{*}{ Ssa197 } & 12 & 8 & F-GGGTGGAGTAGGGAGGCTTG & & & \\
\hline & & & R-TGGCAGGGATTTGACATAAC & 58 & 1.5 & U43694 \\
\hline \multirow[t]{2}{*}{ Ssa213 } & 13 & 19 & F-ATGCTGACTACCCAGATCGAAC & & & \\
\hline & & & R-CTGACACCAAAGAGGAAGAACA & TD & 1.5 & AF019163 \\
\hline \multirow[t]{2}{*}{ Ssa9 } & 14 & 25 & F-GTCAGCCAAACTCCATTGTGAG & & & \\
\hline & & & R-GTGACAACGATTCTGACGACAA & 56 & 1.5 & AF019197 \\
\hline \multirow[t]{2}{*}{ SSsp2210 } & 15 & 6 & F-AAGTATTCATGCACACACATTCACTGC & & & \\
\hline & & & R-CAAGACCCTTTTTCCAATGGGATTC & 58 & 1.5 & AY081818 \\
\hline \multirow[t]{2}{*}{ Ssa420 } & $\mathrm{nu}$ & 5 & F-AGCTCTGGTGGGTACATCATGTG & & & \\
\hline & & & R-GATCTATGCCCACAAACAGACAGG & 58 & 2.0 & AJ402737 \\
\hline \multirow[t]{2}{*}{ Ssa64 } & $\mathrm{nu}$ & 6 & F-GCTGCTCAGCTTTGTCCTCAAG & & & \\
\hline & & & R-TCCTCCTTCTCCAGAATCACCAGG & TD & 1.5 & AF019183 \\
\hline \multirow[t]{2}{*}{ Ssa107 } & $\mathrm{nu}$ & nu & F-GAGAATATGGTCTGCCGAGAGC & & & \\
\hline & & & R-ATGTACGGAGTCCACCCTC & 58 & 1.5 & AY402542 \\
\hline \multirow[t]{2}{*}{ Ssa417 } & nu & 11 & F-CAGACAGGTCCAGACAAGCAC & & & \\
\hline & & & R-CGTCGTTGCTCCTAAACGTTA & TD & 1.5 & AJ402734 \\
\hline \multirow[t]{2}{*}{ Ssa85 } & $\mathrm{nu}$ & 18 & F-TGTCAGACAGATAGCACTGCGG & & & \\
\hline & & & R-GCTCCTCACTTAATCAGATTTC & TD & 1.5 & U43692 \\
\hline
\end{tabular}


Table 1. (continued)

\begin{tabular}{|c|c|c|c|c|c|c|}
\hline Locus & $\begin{array}{l}\text { Linkage } \\
\text { Linkage }\end{array}$ & $\begin{array}{l}\text { e groups } \\
\text { SALMAP }\end{array}$ & Primers & $\begin{array}{c}\text { Annealing } \\
T\left({ }^{\circ} \mathrm{C}\right)\end{array}$ & $\begin{array}{c}\mathrm{MgCl}_{2} \\
\text { conc. (mM) }\end{array}$ & $\begin{array}{l}\text { GenBank } \\
\text { Acc. No. }\end{array}$ \\
\hline \multirow[t]{2}{*}{ Ssa20 } & unl. & 20 & F-TCAGGGGTTTGAATTACATTAG & & & \\
\hline & & & R-ATTGTATGGTCCATGCATGCTG & TD & 1.5 & AF019162 \\
\hline \multirow[t]{2}{*}{ Ssa79 } & nu & 21 & F-CACTCACTGCCAGGCTCTACTGGT & & & \\
\hline & & & R-TCACTACAATGCCAATGCCCA & 58 & 2.5 & AF420543 \\
\hline \multirow[t]{2}{*}{ Ssa13 } & $\mathrm{nu}$ & 23 & F-GCTAAATTGCACCTTGTGATTC & & & \\
\hline & & & R-GTTAGCTAGAGTCTAGACCCGTG & 57 & 2.0 & U58903 \\
\hline \multirow[t]{2}{*}{ Ssa405 } & $\mathrm{nu}$ & 28 & F-TGAGTGGGAATGGACCAGACAG & & & \\
\hline & & & R-ACCATTGTGCCATCTCGTGTCTA & 59 & 2.0 & AJ402722 \\
\hline \multirow[t]{2}{*}{ Ssa68 } & $\mathrm{nu}$ & 22 & F-ACTCTGCTAAAACCAGCCTTCCA & & & \\
\hline & & & R-TCTACAGCAAACAACCCGAGACA & 58 & 2.0 & AF420538 \\
\hline \multirow[t]{2}{*}{ Ssa77 } & $\mathrm{nu}$ & $6 / 2$ & F-GCCATCACCTCACTGTGTGGA & & & \\
\hline & & & R-ACCCTGTTACAAACTGGGCGCA & 58 & 2.0 & AF420553 \\
\hline \multirow[t]{2}{*}{$u F 43$} & unl. & $\mathrm{nu}$ & F-AGCGGCATAACGTGCTGTGT & & & \\
\hline & & & R-GAGTCACTCAAAGTGAGGCC & TD & 1.5 & U37494 \\
\hline \multirow[t]{2}{*}{ Ssleen82 } & unl. & nu & F-CATGGAGAATCCCACTTTCTTA & & & \\
\hline & & & R-CAGGGAGTGATATGGGACATAA & 58 & 1.5 & U86706 \\
\hline \multirow[t]{2}{*}{ SSsp1605 } & unl. & 18 & F-CGCAATGGAAGTCAGTGGACTGG & & & \\
\hline & & & R-CTGATTTAGCTTTTTAGTGCCCAATGC & 58 & 1.5 & AY081812 \\
\hline \multirow[t]{2}{*}{ SSsp2215 } & unl. & 7 & F-ACTAGCCAGGTGTCCTGCCGGTC & & & \\
\hline & & & R-AGGGTCAGTCAGTCACACCATGCAC & 58 & 1.5 & AY081810 \\
\hline \multirow[t]{2}{*}{ SSsp2216 } & unl. & 7 & F-GGCCCAGACAGATAAACAAACACGC & & & \\
\hline & & & R-GCCAACAGCAGCATCATCACCCAG & 58 & 1.5 & AY081811 \\
\hline \multirow[t]{2}{*}{ Rsa172 } & unl. & $\mathrm{nu}$ & F-AACAGTCGCCCTGATGCTATCTCA & & & \\
\hline & & & R-GGCCATGCTACAGAAGCAGAAAGA & 58 & 1.5 & AF271582 \\
\hline \multirow[t]{2}{*}{ Hae050 } & unl. & $\mathrm{nu}$ & F-TTTATCGCGACCCTTATACCCTC & & & \\
\hline & & & R-ATTCTTAGCCCTGGGTCTCTGC & 58 & 1.5 & AF271499 \\
\hline \multirow[t]{2}{*}{ Ssa138 } & unl. & nu & F-GCATGTTTCAGTGCCTTATC & & & \\
\hline & & & R-CTGACTATATCCCAGCCATG & $\mathrm{TD}$ & 1.5 & U58902 \\
\hline \multirow[t]{2}{*}{ Ssa65 } & unl. & 32 & F-GTGGGACATCCCAAGAGAAAG & & & \\
\hline & & & R-ATCCCAGAACACAGGGTAGAG & TD & 1.5 & AF019184 \\
\hline \multirow[t]{2}{*}{ Hae029 } & unl. & $\mathrm{nu}$ & F-AGTCAGCTGGGTCTTGTCTGAGTC & & & \\
\hline & & & R-ACATGCAAGACCTCCAGGACGC & 57 & 2.5 & AF271486 \\
\hline \multirow[t]{2}{*}{ Hae065 } & unl. & $\mathrm{nu}$ & F-TGGTGTAATCATGCTGCAACATC & & & \\
\hline & & & R-CTGAGGAGCAAGACGGAGGTTAGT & 56 & 1.5 & AF271510 \\
\hline \multirow[t]{2}{*}{ Hae085 } & unl. & $\mathrm{nu}$ & F-TAAAGTCCTGGGTACCTGGATGG & & & \\
\hline & & & R-CCTGCTCACAGACACTGTGATGTT & 54 & 1.5 & AF271522 \\
\hline
\end{tabular}

Total genomic DNA was isolated from the adipose tissue samples using chloroform/ethanol extraction (Mullenbach et al. 1989). Microsatellites obtained from the literature were screened following published methods regarding primers, PCR conditions and annealing temperatures. Where possible, primers for the microsatellites obtained directly from the GenBank database were those detailed in the GenBank records. Where the record did not describe primers, they were designed using Primers for the $\mathrm{Mac}^{\odot}$ (Apple $\mathrm{Pi}$ ) (Table 1). All primers were obtained from Life Technologies, Paisley, Scotland. PCR was performed in a $12.5 \mathrm{ul}$ reaction volume containing 5 to $100 \mathrm{ng}$ DNA, $75 \mathrm{mM}$ Tris- $\mathrm{HCl} \mathrm{pH} 8.8,20 \mathrm{mM}\left(\mathrm{NH}_{4}\right)_{2} \mathrm{SO}_{4}, 0.01 \% \mathrm{v} / \mathrm{v}$ Tween, $1.5 \mathrm{mM} \mathrm{MgCl}_{2}, 200 \mu \mathrm{M}$ each dNTP and $0.25 \mathrm{U}$ ABgene Taq DNA polymerase (ABgene). PCR cycling conditions consisted of a modified 'touchdown' sequence (Don et al. 1991) consisting of a denaturing step of $95^{\circ} \mathrm{C}$ for 2 min followed by a series of cycles consisting of $95^{\circ} \mathrm{C}$ for $30 \mathrm{~s}$, annealing temperature for
$30 \mathrm{~s}$ and $72^{\circ} \mathrm{C}$ for $30 \mathrm{~s}$. Annealing temperatures were from 65 to $56^{\circ} \mathrm{C}$, decreasing in $0.5^{\circ} \mathrm{C}$ steps, followed by 20 cycles at $56^{\circ} \mathrm{C}$. PCR was completed with an extension step of $72^{\circ} \mathrm{C}$ for $10 \mathrm{~min}$. PCR products were visualised and sized using $6 \%$ denaturing polyacrylamide electrophoresis followed by silver staining (after Boulikas \& Hancock 1981).

Linkage arrangements of all markers were examined using 'Mapmaker/EXP 3.0b' (Lander et al. 1987) using a minimum LOD (log of odds ratio) score of 3.0. Linkage was examined separately in both families.

Statistical analysis. Tests for single marker-trait associations were performed using general linear modelling (GLM). The traits examined were parasite counts at each sampling point, maximum parasite numbers, and the ratio of maximum to final parasite numbers (to give insight into whether parasite numbers have risen or fallen) - a total of 7 traits. Before analysis, parasite counts were normalised using log transformations. 
For each trait, at each marker, a general linear model containing family, sex and developmental status (i.e. parr or smolt, determined from length frequency histograms) as covariates, was first fitted. This was then compared to a model in which the separate influences of marker alleles inherited from dam and sire were also included. Those marker-trait combinations which showed a significant change in the amount of variance explained when the influence of the marker alleles was incorporated were taken as suggestive of markerQTL linkages. The 2 models were

Part model: $Y_{i j k}=C+f_{i}+s_{j}+d_{k}+e_{i j k}$ and

Full model: $Y_{i j k l m}=C+f_{i}+s_{j}+d_{k}+f_{i}\left(M 1_{l}\right)+f_{i}\left(M 2_{m}\right)+e_{i j k l m}$

where: $Y_{i j k}=$ the phenotypic trait measurement of the $i$ th individual of the $j$ th sex of the $k$ th developmental status (and possessing the lth and $m$ th marker alleles in the full model); $C$ is the constant; $f_{i}$ is the proportion of $Y$ attributable to family; $s_{j}$ is the proportion of $Y$ attributable to the sex of the fish; $d_{k}$ is the proportion of $Y$ attributable to developmental status (parr or smolt); $f_{i}\left(M 1_{l}\right)$ is the proportion of $Y$ attributable to the marker allele inherited from the sire nested within family; $f_{i}\left(M 2_{m}\right)$ is the proportion of $Y$ attributable to the marker allele inherited from dam nested within family; e is the random residual associated with each individual. The marker alleles were included as nested variables within families in order to take into account epistatic interactions which could differ with family backgrounds. The part model allowed estimation of the influence of family, sex and developmental status on the trait in question. The full model included the influence of any QTL linked to the markers, and a comparison of the 2 models allows determination of the magnitude of this influence. The significance of the difference between the 2 models was examined using an $F$-test, with the results of the 5 parasite counts being combined using Fisher's technique (Sokal \& Rohlf 1995). Markers which showed significant associations during the individual marker-trait analysis were then combined in a new GLM which allowed the total amount of variance in parasite numbers associated with the genetic markers identified during the current study to be determined.
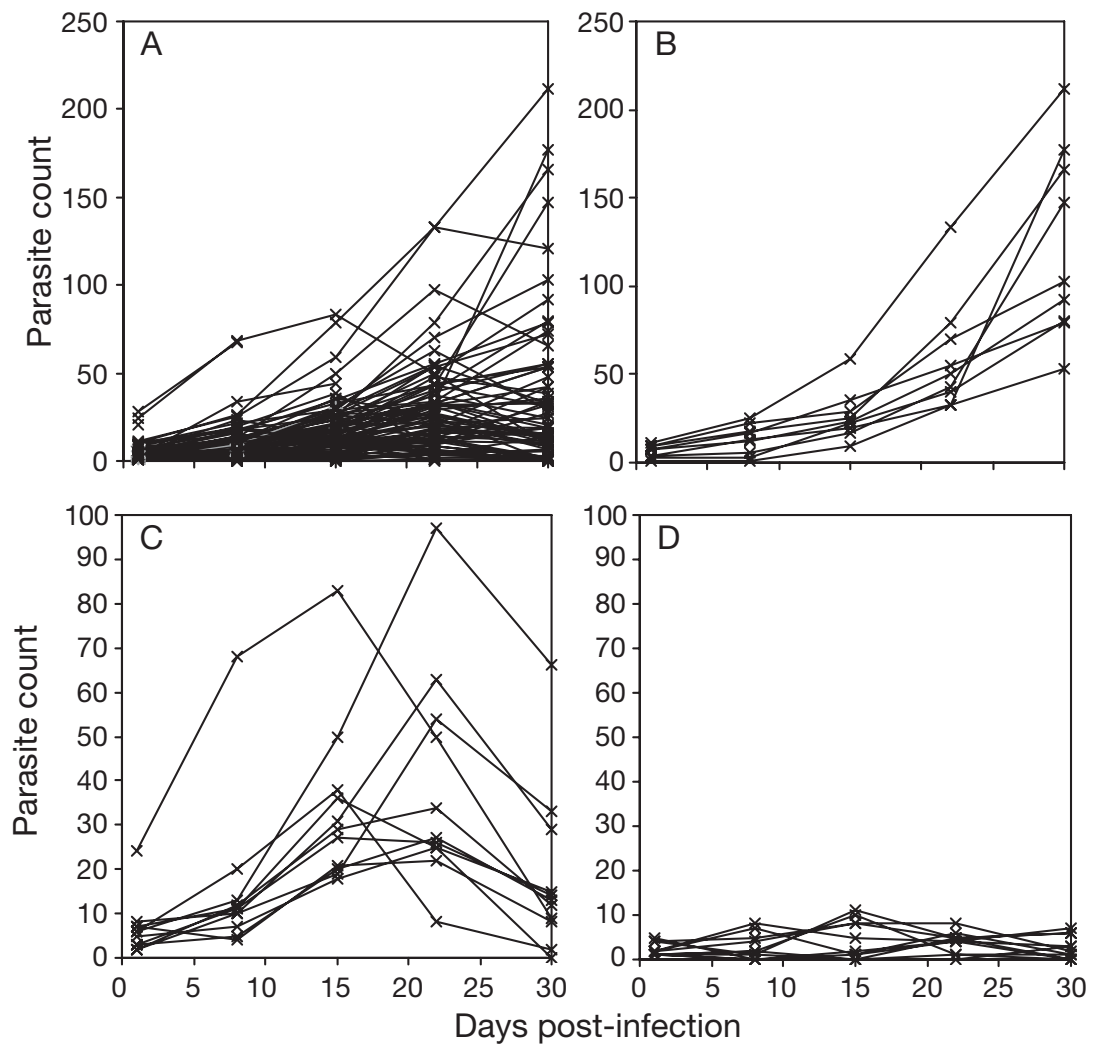

Fig. 1. Salmo salar infected with Gyrodactylus salaris. (A) All fish, showing continuous range of infection profiles; (B) selected 'susceptible' fish, showing exponential-like parasite growth; (C) selected 'responding' fish, showing increase in parasite load to maxima before parasite numbers fall; (D) selected 'resistant' fish, in which parasite load increases little above initial infection numbers

\section{RESULTS}

Fish size (length, weight or condition factor) did not significantly influence parasite numbers at any sampling point, including the initial infection, $p \geq 0.090$. Initial infection levels were an average of $5.0 \pm 4.6 \mathrm{SD}$ parasites fish ${ }^{-1}$. Previously, such initial infection levels have been found to produce representative patterns of resistance/ susceptibility (T. A. Mo unpubl. data). We observed 3 general types of infection profiles: 'susceptible' (Fig. 1B), in which the parasite load increases in an exponential manner; 'responding' (Fig. 1C), in which the parasite load increases to some maximum before falling; and 'resistant' (Fig. 1D), in which the parasite load never builds much above initial levels. Attempts to separate all fish into these 3 groups using multivariate statistics were unsuccessful due to the continuous range of infection profiles observed (Fig. 1A). There were no significant differences in parasite counts between the families at any sampling point ( $\mathrm{p} \geq 0.060)$.

Mapmaker analysis of all markers revealed 11 new linkage arrangements allowing linkage-groups from Gilbey et al. (2004) to be related to those of the SALMAP linkage-map (Table 2). These 
Table 2. Salmo salar. Microsatellite linkage-groups identified during current study. Linkage-groups identified from linkage-map of Gilbey et al. (2004) and linkage-map of SALMAP. unl.: unlinked; ns: non-significant linkage, np: not possible due to parental homozygosity

\begin{tabular}{|lcccc|}
\hline \multirow{2}{*}{ Microsatellites } & \multicolumn{2}{c}{ Recombination rates } & \multicolumn{2}{c|}{ Linkage-group } \\
& Family 1 & Family 2 & Gilbey & SALMAP \\
\hline Ssos1311+ Ssa42 & 0.0612 & 0.0200 & 3 & 2 \\
SSsp2201+ Ssa420 & 0.0 & 0.0 & 9 & 5 \\
SSsp2216+ Rsa172 & 0.1739 & $0.2917^{\mathrm{ns}}$ & unl. & 7 \\
Ssa213+ Ssa417 & 0.0465 & 0.0526 & 13 & 11 \\
Ssa85 + SSsp1605 & 0.2292 & 0.2000 & unl. & 18 \\
Ssa405 + Ssleen82 & 0.0426 & $0.5200^{\text {ns }}$ & unl. & 28 \\
Ssa107 + Hae065 & 0.0200 & 0.0 & unl. & \\
Ssa197 + Hae029 & $0.4618^{\text {ns }}$ & 0.1633 & 12 & 8 \\
Ssa68 + uF43 & $0.4694^{\text {ns }}$ & 0.0667 & unl. & 22 \\
CmrSS1.22 + Ssa13 & np & 0.1111 & 11 & 23 \\
Ssa64 + Ssa77 & np & 0.0 & & 6 \\
\hline
\end{tabular}

include 4 restricted to a single family (where it is possible to make comparisons between families): SSsp2216 + Rsa172; Ssa405 + Ssleen82; Ssa197 + Hae029 and Ssa68 + uF43. These family dissimilarities probably reflect individual male differences in the degree of chromosome homologies being reflected in recombination rate heterogeneity.

There were 10 significant marker-trait associations when the $F$-test significance values of the difference between the part and full models for each count point were combined (Table 3). Of these, 7 were related to parasite counts at the different sampling points, 2 with maximum numbers and 3 with the ratio of final to maximum numbers. The final combined GLMs were run using these significant markers. Parasite counts at the different sampling points were examined using a model which contained Hae029, Ssa171, Ssa405, Ssa42, Ssa68 and Ssa85; maximum numbers with a model containing Hae029 and Ssa420; and the ratio of maximum to final numbers with a model containing Ssa171, Ssa138 and Uf43.

The amount of variance explained by the putative QTL linked to individual and combined markers was determined by the difference between the $\mathrm{R}^{2}$ values of the part and full models (Table 4). Individual markers explained up to $12.3 \%$ of the variation in parasite numbers, up to $9.5 \%$ of the maximum parasite load and up to $10.5 \%$ of the ratio of maximum to final numbers, while the combined GLMs explained from 10.0 to $27.3 \%$ of parasite numbers and 19.3 and $24.2 \%$ of the maximum and ratio of maximum to final numbers respectively.

\section{DISCUSSION}

We have identified multiple genetic markers linked to QTL influencing Gyrodactylus salaris resistance in Atlantic salmon. These markers are located on different linkage-groups and suggest polygenic control of $G$. salaris resistance in Atlantic salmon.

The 3 responses to infection seen in the B1 families established from resistant and susceptible populations have been reported by other investigators. The fish classed as 'susceptible' showed a more or less continuous increase of parasite numbers in an exponential-like growth, similar to that seen with pure Conon and other Scottish and Norwegian fish not previously exposed to the parasite (e.g. Bakke \& Mackenzie 1993, Bakke et al. 2002, Dalgaard et al. 2003). These have no apparent inherent resistance. Fish classed as 'responding' acquired significant parasite numbers until some maximum was reached, after which the parasite load decreased. This pattern is similar to that seen in the pure parental line from the Neva, which is known to be highly resistant. As the parasite load on Neva fish rises, it has been suggested that an acquired host response starts to become effective (e.g. Bakke et al. 1990, Cable et al. 2000) and parasite age-specific mortality and developmental times for parasite embryos increase. As a consequence, no parasites survive to give birth more than once and the population level falls (Cable et al. 2000). In contrast, there were also 'resistant' fish, in which parasite numbers remained more or less at the initial infection level. This response has also been

Table 3. Salmo salar. General linear model results. Values are significance (p) of difference in amount of variance explained by the 2 models at 5 count points; values in bold are significant at $\mathrm{p}<0.05$ level. Combined probability $(\mathrm{Cp})$ is combined significance values for the 5 parasite count points using Fisher's method (Sokal \& Rohlf 1995)

\begin{tabular}{|c|c|c|c|c|c|c|c|c|}
\hline \multirow{2}{*}{$\begin{array}{l}\text { Micro- } \\
\text { satellite }\end{array}$} & \multicolumn{5}{|c|}{ Parasite counts (d post-infection) } & \multirow[t]{2}{*}{$\mathrm{Cp}$} & \multirow{2}{*}{$\begin{array}{c}\text { Max. } \\
\text { no. }\end{array}$} & \multirow{2}{*}{$\begin{array}{l}\text { Max.: } \\
\text { final no }\end{array}$} \\
\hline & 1 & 8 & 15 & 22 & 30 & & & \\
\hline Hae029 & 0.710 & 0.986 & 0.034 & 0.015 & 0.026 & 0.0101 & 0.010 & 0.380 \\
\hline Ssa171 & 0.578 & 0.503 & 0.286 & 0.074 & 0.005 & 0.0227 & 0.159 & 0.011 \\
\hline Ssa405 & 0.051 & 0.292 & 0.275 & 0.312 & 0.042 & 0.0326 & 0.339 & 0.234 \\
\hline Ssa42 & 0.725 & 0.054 & 0.036 & 0.502 & 0.060 & 0.0280 & 0.178 & 0.526 \\
\hline Ssa68 & 0.240 & 0.169 & 0.027 & 0.112 & 0.794 & 0.0475 & 0.278 & 0.150 \\
\hline Ssa85 & 0.020 & 0.041 & 0.181 & 0.375 & 0.791 & 0.0287 & 0.304 & 0.850 \\
\hline SSsp2215 & 0.137 & 0.004 & 0.149 & 0.138 & 0.155 & 0.0031 & 0.082 & 0.390 \\
\hline Ssa138 & 0.981 & 0.454 & 0.298 & 0.141 & 0.234 & 0.3684 & 0.583 & 0.032 \\
\hline Ssa420 & 0.123 & 0.114 & 0.673 & 0.282 & 0.406 & 0.1890 & 0.026 & 0.747 \\
\hline Uf43 & 0.225 & 0.771 & 0.910 & 0.949 & 0.194 & 0.7182 & 0.856 & 0.042 \\
\hline
\end{tabular}


Table 4. Salmo salar. Proportion of variance explained (\% total variance in parasite numbers) by QTL linked to microsatellite markers in S. salar. Combined: combined general linear models that include all markers associated with variance in parasite numbers at each sample point/trait during individual analysis

\begin{tabular}{|c|c|c|c|c|c|c|c|c|}
\hline \multirow{2}{*}{$\begin{array}{l}\text { Micro- } \\
\text { satellite }\end{array}$} & \multicolumn{5}{|c|}{ Parasite counts (d post-innfection) } & \multirow{2}{*}{$\begin{array}{c}\text { Parasite } \\
\text { counts } \\
(\text { mean } \pm \mathrm{SD})\end{array}$} & \multirow{2}{*}{$\begin{array}{l}\text { Max. } \\
\text { no. }\end{array}$} & \multirow{2}{*}{$\begin{array}{c}\text { Max.: } \\
\text { final no. }\end{array}$} \\
\hline & 1 & 8 & 15 & 22 & 30 & & & \\
\hline Нае029 & 0 & 0 & 3.0 & 8.9 & 5.1 & $3.4 \pm 3.8$ & 9.5 & 0 \\
\hline Ssa171 & 0 & 0 & 0 & 5.2 & 12.0 & $3.4 \pm 5.3$ & 2.1 & 10.5 \\
\hline Ssa405 & 5.1 & 1.4 & 0 & 1.2 & 6.1 & $2.8 \pm 2.7$ & 0.1 & 0.4 \\
\hline Ssa42 & 0 & 6.9 & 5.4 & 0 & 4.9 & $3.4 \pm 3.2$ & 2.9 & 0 \\
\hline Ssa68 & 0 & 4.4 & 6.4 & 4.7 & 0 & $3.1 \pm 2.9$ & 0.5 & 2.2 \\
\hline Ssa85 & 6.8 & 6.7 & 0 & 0.3 & 0 & $2.8 \pm 3.6$ & 0.3 & 0 \\
\hline SSsp2215 & 1.3 & 12.3 & 0 & 3.5 & 0.3 & $3.5 \pm 5.1$ & 4.7 & 0 \\
\hline Ssa138 & 0 & 5.5 & 0 & 2.3 & 0 & $1.6 \pm 2.4$ & 0 & 3.4 \\
\hline Ssa420 & 1.7 & 3.7 & 0 & 1.4 & 0 & $1.4 \pm 1.5$ & 8.5 & 0 \\
\hline Uf43 & 0 & 4.6 & 0 & 0 & 0.1 & $1.0 \pm 2.0$ & 0 & 5.3 \\
\hline Combined & 10.0 & 22.1 & 21.9 & 21.1 & 27.3 & $20.5 \pm 6.4$ & 19.3 & 24.2 \\
\hline
\end{tabular}

Ssa68 and Hae029 were associated with infection in the mid and/or later stages, suggesting linkage to QTL involved in acquired resistance. Finally, QTL linked to the 2 remaining markers, Ssa420 and SSsp2215, seem to influence infection throughout the experiment.

A number of studies have previously suggested a polygenic control of Atlantic salmon resistance to infection with Gyrodactylus salaris (e.g. Bakke et al. 1990, 1999, 2002). Indeed, if variations in a number of immunological pathways and host physiologies are involved, which seems likely because of the influence of both innate and acquired resistance, this is unsurprising. No other ectoparasite resistance,

observed in fish from the Neva (Bakke et al. 1990) and when other species of salmonids and non-salmonids have been infected with Gyrodactylus salaris (Bakke 1991). This type of response is suggestive of an innate resistance and has been attributed to host factors such as the alternative complement pathway, acute phase reactants and macrophages which bind to monogeneans such as G. salaris and elicit severe damage to the parasite (Buchmann \& Lindenstrøm 2002). Excess mucus production and a highly proliferative epithelium also interfere with infection (Jones 2001, Buchmann \& Lindenstrøm 2002, Dalgaard et al. 2003) by making passage through the mucus energetically unfavourable for infective stages and by the removal of parasites via sloughing of mucus and/or cells (Jones 2001). This mucus also contains immunoglobulin, complement, C-reactive proteins, lectins, lysozyme and haemolysins, all substances with biostatic or biocidal activity (Yano 1996, Jones 2001). It must be noted, however, that Lindenstrøm et al. (2006) suggest that excess mucus production may actually contribute to parasite population increase in susceptible fish, as the parasites obtain nourishment from such mucus.

The actual responses of the fish screened showed a continuous range of patterns of infestation (Fig. 1), as expected in this type of cross if resistance to infection is under polygenic control. This view is supported by the QTL analysis, which identified a total of 10 markers for linkage-groups with QTL influencing infection. Single marker-trait associations were found to explain up to $12.3 \%$ of the variation in parasite numbers at single sample points. However, the amount explained by each marker varied with the ontogeny of the infection. Ssa85, Ssa77 and SSsp2216 were associated with infection in the early stages, suggesting involvement in innate resistance. In contrast, Ssa171, Ssosl311, Ssa42,
QTL mapping studies have been performed with Atlantic salmon, but resistance to the myxozoan endoparasite Ceratomyxa shasta Noble has been examined in rainbow trout Oncorhynchus mykiss Walbaum. Ibarra et al. $(1992,1994)$ showed that inheritance of resistance was polygenic and involved significant additive, dominant and digenic interaction effects and that the nature of the different genetic components differed during the ontogeny of infection, as in the current study. Nichols et al. (2003), in a QTL mapping study similar to the current analysis, identified up to 8 unlinked markers associated with putative QTL influencing this trait, even though the trait was binary (i.e. live/dead fish).

The QTL associated in the present study with Gyrodactylus salaris resistance in salmon show an exponential distribution in their effects. However, QTL studies identify large effects before small ones, potentially making such a distribution artifactual. Also, estimates of QTL effect can be upwardly biased, especially for loci with large effects (Melchinger et al. 1998, Goring et al. 2001), so the true effect of a QTL may be smaller than the experimental estimate. Finally, estimates of numbers and effects of QTL are really estimates of numbers and effects of chromosomal regions; each region might contain hundreds or thousands of genes. As such, estimated single locus large effects might actually be due to additive small effects of many loci. This latter qualification is especially relevant to the present study, as the markers used here represent entire linkage groups, which may even be complete chromosomes (Gilbey et al. 2004). However, further fine-scale mapping is required to determine the true number and strengths of the factors involved.

Despite these qualifications, ranking of QTL according to their effects at the different time points reveals 
significant exponential distributions in ranked marker/trait influences at each point. Exponential regression equations (in the form $y=\mathrm{ae}^{-b x}$ ) were fitted
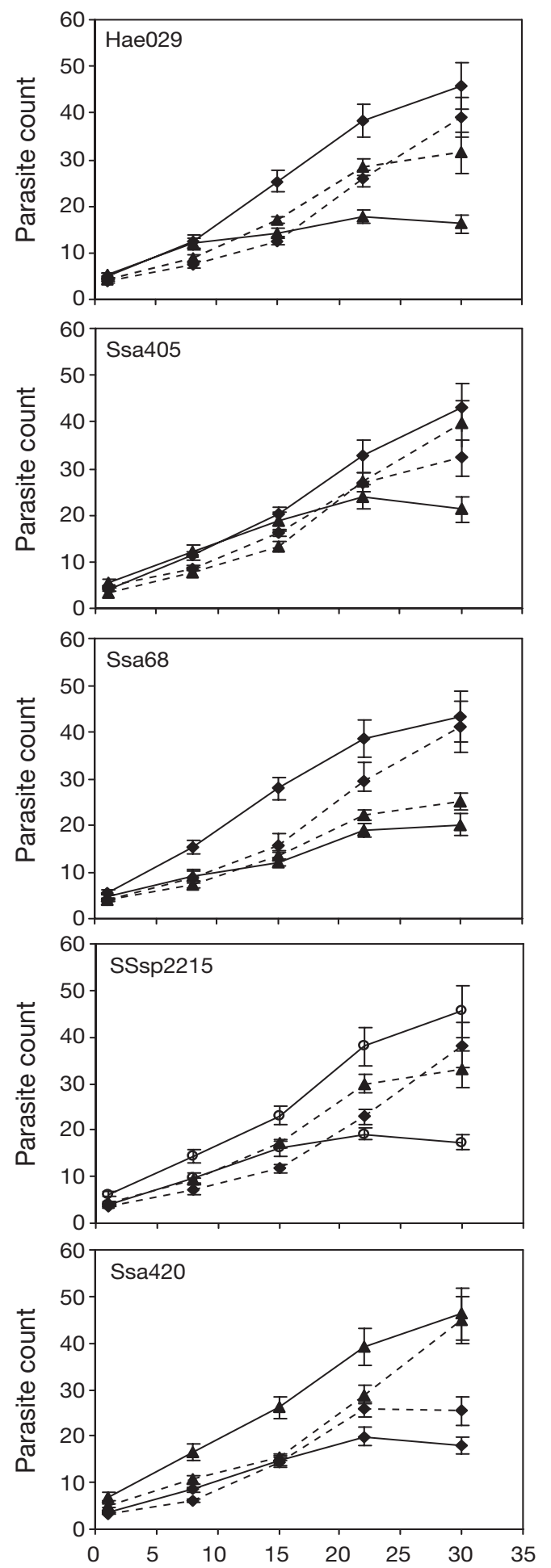

to ranked marker/trait influences effects at 1, 8, 22 and $30 \mathrm{~d}$ post-fertilisation (those sample times for which sufficient loci were identified as influencing resistance
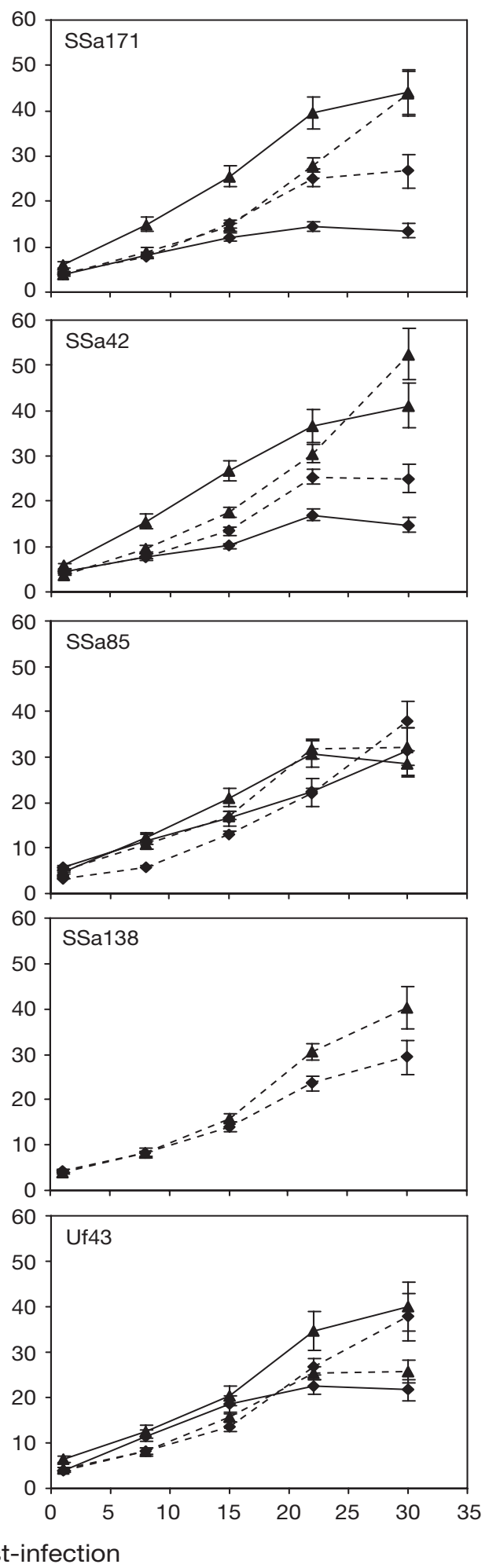

Fig. 2. Salmo salar infected with Gyrodactylus salaris. Mean $\pm 95 \%$ CI parasite infection patterns associated with alternate paternally inherited marker alleles (and maternally inherited in Locus SSsp2215). Continuous lines: Family 1 (Neva female parent); dashed lines: Family 2 (Conon female parent). ( ) alleles inherited from Neva groundparental line; $(\mathbf{\Delta})$ alleles inhherited from Conon grandparental line; (O) in SSsp2215 relate to alternate maternally inherited alleles in Family 1 
to fit such a regression). At all sample times the regressions are significant $(p \leq 0.037)$ with $R^{2}$ values $\geq 0.960$. The distribution of QTL effects found in the present study are thus in agreement with the exponentially declining effects model for QTL (see Orr 1998, Hayes \& Goddard 2001, Barton \& Keightley 2002, and references therein).

The distribution of QTL effects has implications for breeding programmes. Single genes of major effects are most amenable to marker-assisted selection (MAS) (Lande \& Thompson 1990). Markers or alleles can be readily identified and MAS used to incorporate resistance alleles at major QTL into the selected line. Inclusion of such major gene resistance alleles could thus be achieved in a few generations, quickly boosting a population's resistance to the parasite. This boost may be enough to allow the fish to coexist with Gyrodactylus salaris in the wild, when natural selection will then be able to select for other QTL with smaller effects, that are much harder to identify and to incorporate into breeding programmes.

Marker-assisted selection of native broodstock to influence a phenotypic trait relies on the availability of heritable variation within the population under selection. The results of the present study suggest that in both the source populations utilised as broodstock such variation exists. Fig. 2 details the parasite counts associated with alternate alleles inherited from the informative hybrid male parents at the markers found to be linked to QTL that significantly influence resistance. The largest differences in parasite numbers associated with the inheritance of alternate alleles is consistently seen when these alleles are expressed in Family 1, in which the hybrid males were backcrossed to a Neva female. These differences are less pronounced, but still significant, in Family 2, in which the hybrid males were backcrossed to a Conon female. These differences suggest that some kind of epistatic interaction is occurring; however, the significance of the interactions between male and female genotypes is hard to quantify. Attempts to examine interaction terms in GLM or ANOVA models were unsuccessful due to the small numbers of fish in each group when family/female/male alleles were separated. It would be interesting to examine these effects in larger experimental groups.

Genotyping of the pure-strain grandparents of the experimental generation allowed identification of the origin of the alleles inherited from the hybrid F1 males. It was expected, a priori, that the more resistant fish might be associated with the possession of alleles originating from the resistant Neva grandparental line. However, while this pattern was observed with some of the markers (e.g. Ssa171) this was found not to be the case for many of the markers identified. For exam- ple, in Family 1 at the Hae029 marker, fish inheriting the grandparental Conon allele had significantly lower parasite numbers than fish with the grandparental Neva allele, even in a Neva female background. It is a QTL originating from the Conon line that is conferring increased resistance in these fish. Further evidence for the possession of markers linked to QTL conferring differential resistance within the pure strains is seen in Family 1 with marker SSsp2215. In this case the hybrid male was homozygous at $S S s p 2215$, but significant differences in resistance were found to be associated with alternate versions of the marker alleles inherited from the pure Neva female parent (the only time this occurred with female alleles). These results suggest that fish from both the Neva and Conon lines are polymorphic with respect to QTL influencing resistance, and as such both strains may be susceptible to breeding schemes designed to enhance resistance using native fish only.

This is the first study to evaluate the genetic basis of resistance to Gyrodactylus salaris using molecular markers. We found multiple genome regions involved in resistance that explained up to $17.6 \%$ of the variation in parasite numbers infecting the fish. The relatively high levels of variation explained by the putative QTL linked to the microsatellite markers, together with the polymorphic nature of resistance alleles within stock types, suggest that a future 'marker-assisted selection' breeding programme has the potential to greatly improve the resistance of both wild and farmed fish to G. salaris.

Acknowledgements. This work was carried out as part of the EU funded SALMOGRYO project, contract number QLRT2000-01631.

\section{LITERATURE CITED}

Bakke TA (1991) A review of the interspecific and intraspecific variability in salmonid hosts to laboratory infections with Gyrodactylus salaris Malmberg. Aquaculture 98: 303-310

Bakke TA, MacKenzie K (1993) Comparative susceptibility of native Scottish and Norwegian stocks of Atlantic salmon, Salmo salar L., to Gyrodactylus-salaris Malmberg - laboratory experiments. Fish Res 17:69-85

Bakke TA, Jansen PA, Hansen LP (1990) Differences in the host-resistance of Atlantic salmon, Salmo salar L., stocks to the monogenean Gyrodactylus-salaris Malmberg, 1957. J Fish Biol 37:577-587

Bakke TA, Soleng A, Harris PD (1999) The susceptibility of Atlantic salmon (Salmo salar L.) $\times$ brown trout $($ Salmo trutta L.) hybrids to Gyrodactylus salaris Malmberg and Gyrodactylus derjavini Mikailov. Parasitology 119: 467-481

Bakke TA, Harris PD, Cable J (2002) Host specificity dynamics: observations on gyrodactylid monogeneans. Int J Parasitol 32:281-308 
Bakke TA, Harris PD, Hansen H, Cable J, Hansen LP (2004) Susceptibility of Baltic and East Atlantic salmon Salmo salar stocks to Gyrodactylus salaris (Monogenea). Dis Aquat Org 58:171-177

Barton NH, Keightley PD (2002) Understanding quantitative genetic variation. Nature Rev Genet 3:11-21

Boulikas T, Hancock R (1981) A highly sensitive technique for staining DNA and RNA in polyacrylamide gels using silver. J Biochem Biophys Methods 5:219-228

Buchmann NK, Lindenstrøm T (2002) Interactions between monogenean parasites and their fish hosts. Int J Parasitol 32:309-319

Cable J, Harris PD, Bakke TA (2000) Population growth of Gyrodactylus salaris (Monogenea) on Norwegian and Baltic Atlantic salmon (Salmo salar) stocks. Parasitology 121:621-629

Christensen O, Larsson PO (1979) Review of Baltic salmon research. Int Counc Explor Sea Coop Res Rep 89

Dalgaard MB, Nielsen CV, Buchmann K (2003) Comparative susceptibility of two races of Salmo salar (Baltic Lule river and Atlantic Conon river strains) to infection with Gyrodactylus salaris. Dis Aquat Org 53:173-176

Dalgaard MB, Larsen TB, Jørndrup S, Buchmann K (2004) Differing resistance of Atlantic salmon strains and rainbow trout to Gyrodactylus salaris infection. J Aquat Anim Health 16:109-115

Dobson AP, May RM (1987) The effects of parasites on fish populations - theoretical aspects. Int $\mathrm{J}$ Parasitol 17: 363-382

Don RH, Cox PT, Wainwright BJ, Baker K, Mattick JS (1991) Touchdown PCR to circumvent spurious priming during gene amplification. Nucleic Acids Res 19:4008

Gilbey J, Verspoor E, McLay A, Houlihan D (2004) A microsatellite linkage map for Atlantic salmon (Salmo salar). Anim Genet 35:98-105

Goring HHH, Terwilliger JD, Blangero J (2001) Large upward bias in estimation of locus-specific effects from genomewide scans. Am J Hum Genet 69:1357-1369

Hayes B, Goddard ME (2001) The distribution of the effects of genes affecting quantitative traits in livestock. Genet Sel Evol 33:209-229

Ibarra AM, Hedrick RP, Galla AE (1992) Inheritance of susceptibility to Ceratomyxa shasta (Myxozoa) in rainbow trout and the effect of length of exposure on the liability to develop ceratomyxosis. Aquaculture 104:217-229

Ibarra AM, Hedrick RP, Galla AE (1994) Genetic analysis of rainbow trout susceptibility to the myxosporean, Ceratomyxa shasta. Aquaculture 120:239-262

Jansen PA, Bakke TA (1993a) Regulatory processes in the monogenean Gyrodactylus salaris-Atlantic salmon (Salmo salar L.) association. 1. Field studies in south-east Norway. Fish Res 17:87-101

Jansen PA, Bakke TA (1993b) Regulatory processes in the monogenean Gyrodactylus salaris-Atlantic salmon (Salmo salar L.) association. 2. Experimental studies. Fish Res 17:103-114

Johnsen BO (1978) The effect of an attack by the parasite Gyrodactylus salaris on the population of salmon parr in the river Lakselva, Misvaer in Northern Norway. Astarte 11:7-9

Johnsen BO, Jensen AJ (1991) The Gyrodactylus story in Norway. Aquaculture 98:289-302

Johnson KR, Wright JE, May B (1987) Linkage relationships reflecting ancestral tetraploidy in salmonid fish. Genetics 116:579-591

Jones CS, Lockyer AE, Verspoor E, Secombes CJ, Noble LR (2002) Towards selective breeding of Atlantic salmon for sea louse resistance: approaches to identify trait markers. Pest Manag Sci 58:559-568

Jones SRM (2001) The occurrence and mechanisms of innate immunity against parasites in fish. Dev Comp Immunol 25: $841-852$

Lande R, Thompson R (1990) Efficiency of marker-assisted selection in the improvement of quantitative traits. Genetics 124:743-756

Lander ES, Green P, Abrahamson J, Barlow A, Daly MJ (1987) Mapmaker: an interactive computer package for constructing primary genetic linkage maps of experimental and natural populations. Genomics 1:174-181

Lindenstrøm T, Sigh J, Dalgaard MB, Buchmann K (2006) Skin expression of $I L-1$ beta in East Atlantic salmon, Salmo salar L., highly susceptible to Gyrodactylus salaris infection is enhanced compared to a low susceptibility Baltic stock. J Fish Dis 29:123-128

McConnell SK, O'Reilly P, Hamilton L, Wright JM, Bentzen P (1995) Polymorphic microsatellite loci from Atlantic salmon (Salmo salar), genetic differentiation of North American and European populations. Can J Fish Aquat Sci 52:1863-1872

Melchinger AE, Utz HF, Schon CC (1998) Quantitative trait locus (QTL) mapping using different testers and independent population samples in maize reveals low power of QTL detection and large bias in estimates of QTL effects. Genetics 149:383-403

Mo TA (2004) The Gyrodactylus salaris situation in Norway: an update on current distribution and eradication programme implemented. In: Buchmann K (ed) Diagnosis and control of fish diseases. SCOFDA Workshop, Royal Veterinary and Agricultural University, Frederiksberg C. Denmark, p 18

Mo TA, Norheim K (2005) The surveillance and control programme for Gyrodactylus salaris in Atlantic salmon and rainbow trout in Norway. In: Mørk T, Hellberg H (eds) Surveillance and control programmes for terrestrial aquatic animals in Norway. Annu Rep 2004. National Veterinary Institute, Oslo, Norway, p 137-139

Moen T, Hoyheim B, Munck H, Gomez-Raya L (2004) A linkage map of Atlantic salmon (Salmo salar) reveals an uncommonly large difference in recombination rate between the sexes. Anim Genet 35:81-92

Mullenbach R, Lagoda PJ, Welter C (1989) An efficient saltchloroform extraction of DNA from blood and tissues. Trends Genet 5:391

Nichols KM, Bartholow JM, Thorgaard GH (2003) Mapping multiple genetic loci associated with Ceratomyxa shasta resistance in Oncorhynchus mykiss. Dis Aquat Org 56: $145-154$

NOU (Norges Offentlige Utredninger) (1999) Til laks åt alle kan ingen gjera? Om årsaker til nedgangen i den norske villaksbestandene og forslag til strategier og tiltak for å bedre situasjonen. Utredning fra utvalg oppnevnt ved kongelig resolusjon av 18. juli 1977. Norges Offentlige Utredninger, Miljøverdepartementet, Oslo, p 1-297

Orr HA (1998) The population genetics of adaptation: the distribution of factors fixed during adaptive evolution. Evolution 52:935-949

Pickering AD (1987) Stress responses and disease resistance in farmed fish. In: Aqua Nor 87. Trondheim International Conference. Norske Fiskeoppdretternes ForeningFiskeoppdrettones, Salgslay A/L Trondheim, Norway, p 36-49

Rintamäki-Kinnunen P, Valtonen ET (1996) Finnish salmon resistance to Gyrodactylus salaris - a long-term study. Int J Parasitol 26:723-732 
Sokal RR, Rohlf FJ (1995) Biometry: the principles and practice of statistics in biological research, 3rd edn. WH Freeman \& Co, New York

Soleng A, Bakke TA (1995) Salinitetstoleransen til Gyrodactylus salaris Malmberg, 1957: spredningspotensiale og sikringssoner. Utredning for Direktoratet for Naturforvaltning (DN), Trondheim, 1:111-116

Stahl G (1987) Genetic population structure of Atlantic salmon. In: Ryman N, Utter F (eds) Population genetics and fishery management. University of Washington Press, London, p 121-140

Stahl G, Hindar K (1988) Genetisk struktur hos norsk laks: status og perspektiver. Rapp Fiskeforskningen. 1. Direktoratet for Naturforvaltning, Utredning for DN, Trond-

Editorial responsibility: Robin Overstreet,

Ocean Springs, Massachusetts, USA heim, Norway. 1:1-57

Williams K, Bogacki P, Scott L, Karakousis A, Wallwork H (2001) Mapping of a gene for leaf scald resistance in barley line 'B87/14' and validation of microsatellite and RFLP markers for marker-assisted selection. Plant Breed 120: 301-304

Wright JE, Johnson KR, Hollister A, May B (1983) Meiotic models to explain classical linkage, pseudolinkage, and chromosome pairing in tetraploid derivative salmonid genomes. Isozymes Curr Top Biol Med Res 10:239-260

Yano T (1996) The nonspecific immune system. In: Iwama G, Nakanishi $\mathrm{T}$ (eds) The fish immune system, organism, pathogen and environment. Academic Press, San Diego, p 105-157

Submitted: March 2, 2006; Accepted: April 19, 2006

Proofs received from author(s): July 18, 2006 